\title{
Pneumatic-Piezoelectric Hybrid Vibration Suppression For a Flexible Translating Beam Using Adaptive Fuzzy Sliding Mode Control Algorithm
}

\author{
Zhi-cheng Qiu \\ School of Mechanical and Automotive Engineering, South China University of Technology, Guangzhou 510641, \\ PR China, \\ State Key Laboratory of Robotics, Shenyang Institute of Automation, Chinese Academy of Sciences, Shenyang \\ 110016, PR China.
}

Bin Wang and Xian-min Zhang

School of Mechanical and Automotive Engineering, South China University of Technology, Guangzhou 510641, PR China.

\author{
Jian-da Han \\ State Key Laboratory of Robotics, Shenyang Institute of Automation, Chinese Academy of Sciences, Shenyang \\ 110016, PR China.
}

(Received 1 November 2014; accepted 2 July 2015)

\begin{abstract}
A translating flexible beam system driven by a rodless cylinder using a proportional valve is proposed. Active vibration control of the flexible beam is developed by using a pneumatic cylinder and a surface-bonded piezoelectric actuator. The experimental test bed constitutes a pneumatic circuit, piezoelectric control system, and corresponding interface circuits. Then, a proportional derivative (PD) controller and an adaptive fuzzy sliding mode control (AFSMC) algorithm are designed and applied to vibration control of the experimental system. Experiments are conducted for set-point residual vibration suppression and resonant vibration control under the excitation of the first mode. The experimental results indicate that the designed controllers can increase the damping of the system to damp out the residual vibration and minimize certain resonant responses.
\end{abstract}

\section{INTRODUCTION}

Pneumatic drive systems are widely used in industrial systems owing to their ease of maintenance and cleaning. However, pneumatic systems suffer from several drawbacks, such as 1 nonlinear friction force and highly nonlinear pneumatic system dynamics. ${ }^{1}$ The nonlinearities in the pneumatic system are mainly the couplings between the pressure and the motion, the flow rate, and the friction force. ${ }^{2}$ Moreover, for a longstroke pneumatic rodless cylinder, higher nonlinear dynamics due to a large operation range may occur; thus, it is difficult to design an effective controller. ${ }^{3}$ Besides, the highly nonlinear flow through pneumatic components and the pressure dropping and time-delay along the connecting tube also result in control errors. ${ }^{4}$ For complicated nonlinear pneumatic servo systems, the conventional PD controller shows a poor capacity to cope with; it may not give a satisfactory control performance. To overcome the above-mentioned problems, control algorithms should be investigated to guarantee the robustness and performance of the pneumatic control system.

To deal with some of the above-mentioned problems, several advanced schemes were utilized to control the pneumatic servo system. A fuzzy gain scheduler of the local state feedback controller was designed for servo-pneumatic actuators.2 Robust loop shaping-fuzzy gain scheduling control (RLSFGS) was applied to design a nonlinear controller for a long-stroke pneumatic system. ${ }^{3}$ A combined discrete variable structure control with self-tuning adaptive control was developed for positioning control strategies of a pneumatic cylinder and a piezoelec- tric actuator. ${ }^{5}$ Further, a kind of multiple-surface sliding controller was designed for pneumatic servo systems. ${ }^{6}$ The sliding mode control was employed to guarantee the robustness of the pneumatic servo system; however, chattering problem occurred in this type of controller. With the idea of the sliding mode control, a direct adaptive fuzzy sliding mode controller was designed by combining a direct adaptive fuzzy control and a fuzzy sliding mode control to reduce the tracking error and chattering. ${ }^{7,8}$ Adaptive fuzzy sliding mode controller was also applied for vibration control of magnetorheological mount. ${ }^{9}$ As for active vibration control of flexible piezoelectric manipulators driven by pneumatic actuators, it is a complicated, rigid-flexible coupling dynamic system, which includes the interaction of a rigid body motion, flexural vibration of flexible manipulators, and highly nonlinear pneumatic actuator dynamics. $^{10}$

Compared with previous works, the major contributions of this work are follows: (a) The pneumatic drive translating flexible piezoelectric beam system is controlled by using a proportional valve to meter the exhaust flow. The hybrid pneumatic and piezoelectric control strategy is utilized to suppress the vibration of the flexible beam. (b) An adaptive fuzzy sliding mode control algorithm is applied to enhance the robustness and adaptability of the complicated control system. (c) Experiments are conducted using this designed adaptive fuzzy sliding mode control, and its results are compared with those of the PD controller. 


\section{PNEUMATIC DRIVING FLEXIBLE MANIPULATOR}

\subsection{Configuration of a Composite Pneumatic and Piezoelectric Driving Flexible Beam System}

Figure 1(a) depicts the schematic diagram of the pneumatic drive piezoelectric flexible beam system. The system is composed of a pneumatic rodless cylinder, piezoelectric flexible beam, pneumatic drive circuit, grating displacement sensor, data acquisition and control components realized by an ARM controller (Mini2440) with corresponding peripheral extending circuits, and computer. The ARM board communicates with the computer. The flexible beam can translate in the horizontal direction driven by the pneumatic rodless cylinder. The cylinder is fixed to the base. The grating displacement sensor is also fixed to the base, which is used to measure the translating displacement of the slider.

The slider's displacement is measured by using the grating displacement sensor, which is calculated using a counter circuit. The PZT sensor can measure the excited vibration of the flexible translating beam, and it is conditioned by a charge amplifier (YE5850). Then, it is converted into digital data through an analogue-to-digital (A/D) converter. The control action of the proportional valve is realized by a digitalto-analogue (D/A) converter connected to the ARM board and the corresponding circuit. The D/A converter can provide two channels: one converts the analogue signal that is modulated to $-5 \mathrm{~V} \sim+5 \mathrm{~V}$ by the peripheral circuit for the PZT actuator; and the other converts the analogue signal that is modulated to $0 \mathrm{~V} \sim+5 \mathrm{~V}$ for the proportional valve. A high-voltage amplifier (APEX PA240CX) amplifies the output signal from $5 \mathrm{~V} \sim+5 \mathrm{~V} V$ to $-130 \mathrm{~V} \sim+130 \mathrm{~V}$ for driving the PZT actuator.

Unlike the previous work, ${ }^{10}$ a proportional valve is used instead of the PCM valve to control the pneumatic cylinder. A throttle valve $S_{1}$ is connected to the proportional valve by cascade connection to limit the rate of flow. A 5-2 way solenoid valve is utilized to dominate the translational direction of the rodless cylinder.

As shown in Fig. 1, $P_{1}$ and $P_{2}$ indicate the two-chamber pressures of this cylinder, respectively; $V_{1}$ and $V_{2}$ denote the two chambers' volumes, respectively. $y(t)$ is the translational displacement of the slider. An air supply source $P_{S}$ can provide compressed air by an air pump. Then, it is divided into three air flows, each connecting with a relief valve. The relief air flows, $P_{S 1}$ and $P_{S 2}$, connect to the two ports of the 5-2 way solenoid switching valve directly, which is used as an air source to drive the motion of the slider in the positive and negative direction. $P_{S 0}$ is utilized as the back pressure of the exhaust chamber, connecting to a check valve. The check valve is connected to one port of the 5-port valve and the intake port of the proportional valve. The other two ports of the 5-port valve are connected to those of the rodless cylinder, respectively.

One side of the flexible beam is clamped into the cylinder's slider. Fig. 1(b) and Fig. 1(c) show an established coordinate system to describe the flexible beams motion. The $X$-axis and the $Y$-axis are in the longitudinal direction and in the translating direction of the slider in the horizontal plane, respectively. The coordinate frame $X O Y$ is attached to the slider. The $Z$ axis is specified in the vertical direction. The translational displacement of the slider is denoted by $y(t)$. The total moving components' mass except for the piezoelectric beam is denoted as $m_{b}$. An accelerometer is fixed at the free end, and its mass

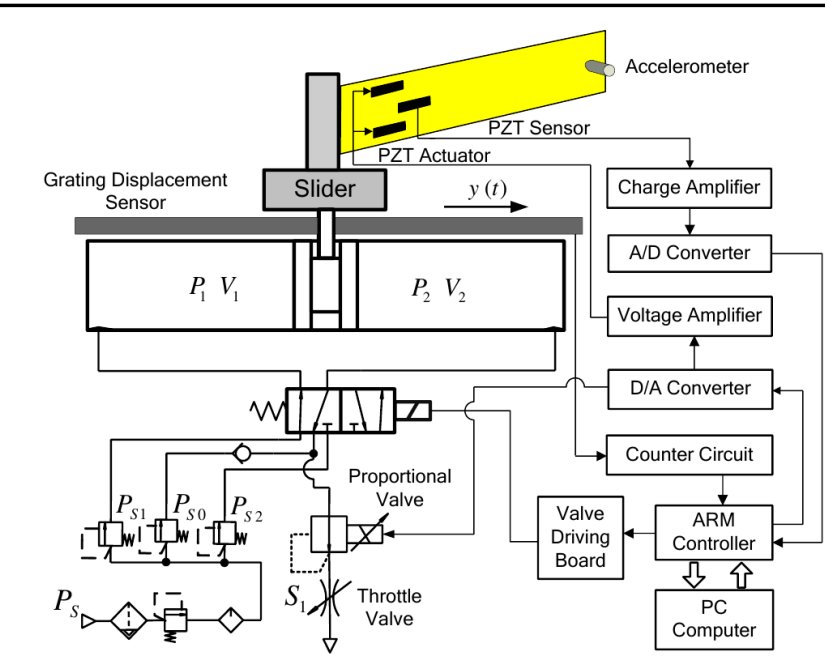

(a) Schematic diagram of the system.

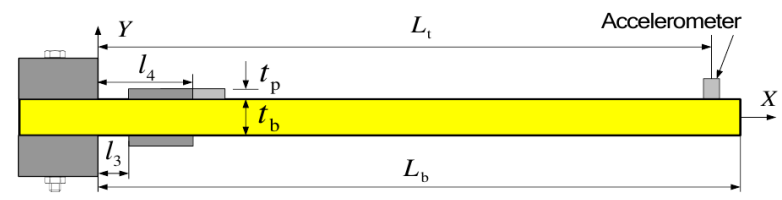

(b) Physical configuration diagram of the flexible beam in $\mathrm{x}-\mathrm{y}$ plane.

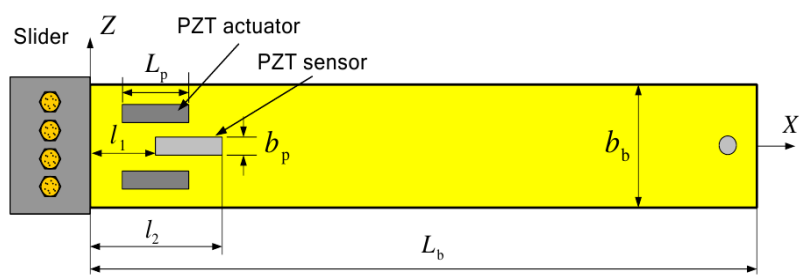

(c) Physical configuration diagram of the flexible beam structure in $\mathrm{X}-\mathrm{z}$ plane.

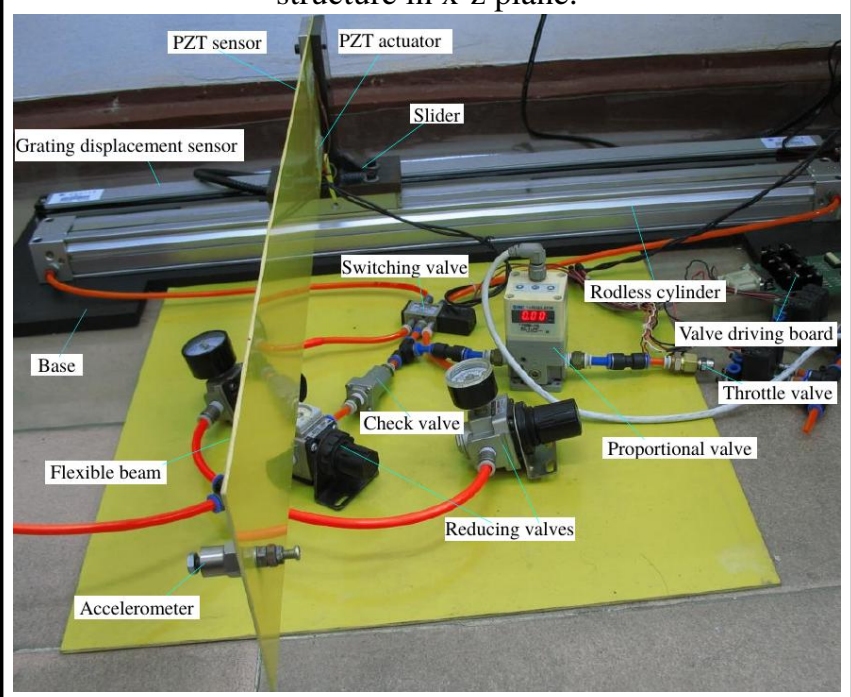

(d) Photograph of the experimental apparatus.

Figure 1. Pneumatic drive piezoelectric flexible beam system.

is $m_{t}$. It is considered as a concentrated payload. The distance between the accelerometer and the clamped side is $L_{t}$.

The distance of the PZT sensor's left edge to the clamped side is $l_{1} . l_{2}$ is the distance of the PZT sensor's right edge to the clamped side. $l_{3}$ and $l_{4}$ are the distance of the PZT actuators. $L_{b}, b_{b}$, and $t_{b}$ are the length, width, and thickness of the flexible beam, respectively. $L_{p}, b_{p}$, and $t_{p}$ indicate the 


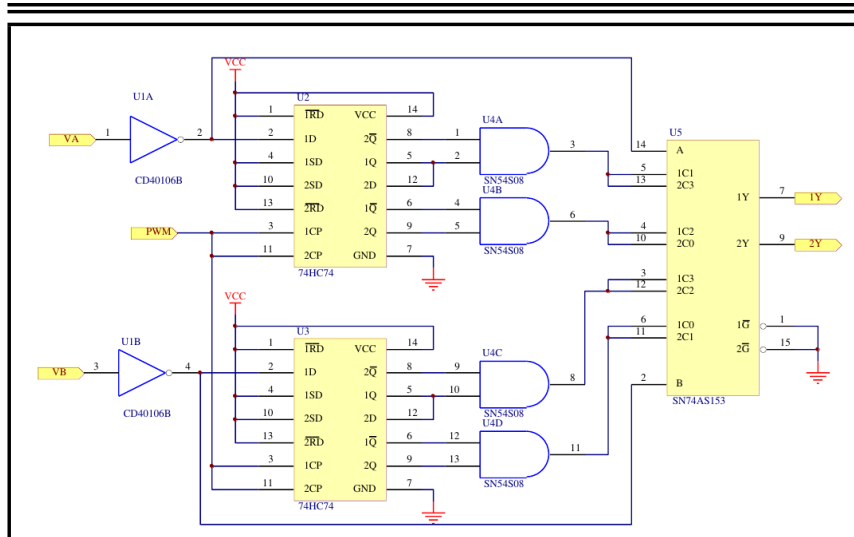

(a) Direction identify and frequency multiplier Circuit.

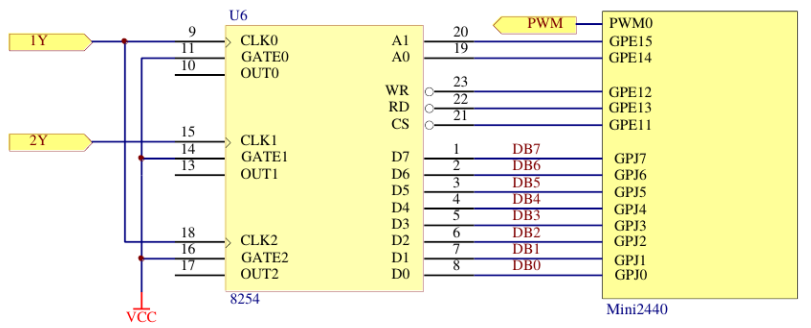

(b) Interface diagram of 8254 and Mini2440.

Figure 2. Corresponding interface circuits of the counter.

length, width, and thickness of the PZT sensor, respectively.

As shown in Fig. 1(a), the displacement of the slider is measured by the grating displacement sensor, and it is calculated by a counter (counter/timer chip Intel 8254). The signal of the grating displacement sensor is tuned by a direction identify and frequency multiplier circuit, as shown in Fig. 2(a). Then, the tuning signal is transmitted to the ARM board via the counter chip (8254). The interface diagram of 8254 and Mini2440 is shown in Fig. 2(b).

The PZT sensor is used to measure the excited vibration of the flexible beam. The measured vibration signal is conditioned by a charge amplifier (YE5850). The obtained voltage signal is in the range of $-10 \mathrm{~V} \sim+10 \mathrm{~V}$, and is converted into digital data through an A/D converter (4-channel chip A/D7862, with 12-bit resolution). The interface diagram of AD7862 and Mini2440 is shown in Fig. 3. Then, both the measured signals are sent to the ARM board.

A composite driving scheme is employed for simultaneous positioning and vibration control by combining both pneumatic cylinder and PZT actuator. The control values are figured out by the designed control algorithms and applied to the proportional valve and the PZT actuator. The control action of the proportional valve is realized by a D/A converter (2channel chip AD7847, with 12-bit resolution) connected with the ARM board and the corresponding circuit. The D/A converter can provide two channels: one converted analogue signal is modulated to $-5 \mathrm{~V} \sim+5 \mathrm{~V}$ by the peripheral circuit for the PZT actuator; and the other converted analogue signal is modulated to $0 \mathrm{~V} \sim+5 \mathrm{~V}$ for the proportional valve. The interface diagram of AD7847 and Mini2440 is shown in Fig. 4.

\subsection{Experimental Apparatus}

An experimental setup is constructed and its photograph is displayed in Fig. 1(d). In the pneumatic circuit, the air compressor (SLG50, Boteli Machinery) can provide an exhaust pressure of $0.8 \mathrm{MPa}$. The pneumatic triplet is made in SMC

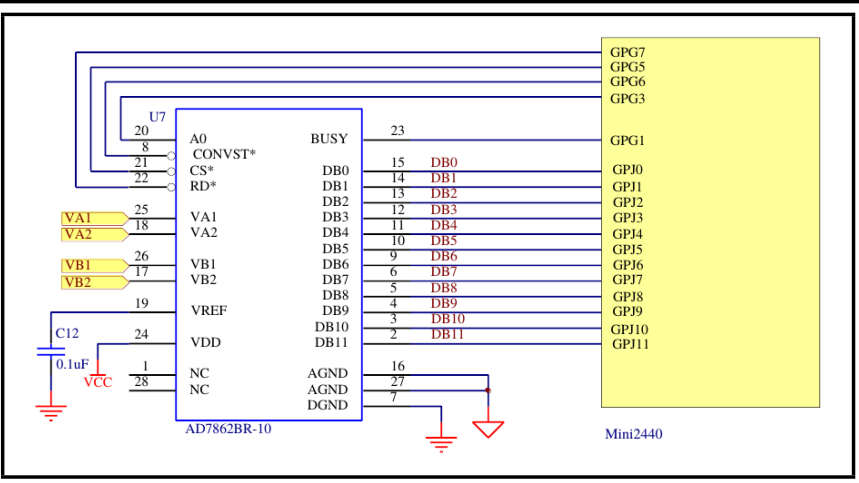

Figure 3. Interface diagram of AD7862 and Mini2440.

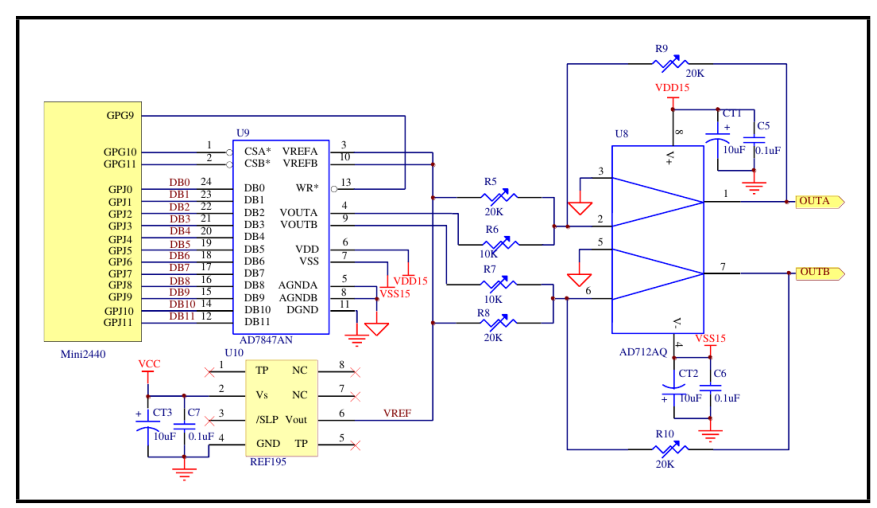

Figure 4. Interface circuit diagram of AD7847 and Mini2440.

Corporation. The pneumatic rodless cylinder (MYIM25-600L, SMC Corporation) is used to drive the slider. Three relief valves (AR2500) are used to tune the pressure to the suitable values. After reducing valves, $P_{1}=P_{2}=0.5 \mathrm{MPa}$, and $P_{0}=0.3 \mathrm{MPa}$. A check valve (Ak2000) is used in the pneumatic circuit to make the exhausted air 0flow through the proportional valve.

A 5-2 way switching valve (VK3120, SMC Corporation) is applied to control the slider's moving direction. The switching solenoid value is driven by the valve driving board with a $24 \mathrm{~V}$ electric source. A proportional valve (ITV2050-212L, SMC Corporation) together with a throttle valve is utilized to meter the exhaust flow. The constant throttle diameter of the throttle valve is $0.79 \mathrm{~mm}$.

A grating displacement sensor (MKT-82, FAGOR Corporation) is used to measure the displacement of the slider. A charge amplifier (YE5850) amplifies the measured vibration of the flexible beam to the range of $-5 \mathrm{~V} \sim+5 \mathrm{~V}$. The output relationship of the charge amplifier is $0.1 \mathrm{mV} / \mathrm{Unit}$, and its sensi-

Table 1. Properties and geometric size of the flexible beam and the PZT patch.

\begin{tabular}{|c|c|c|c||}
\hline Symbol & Parameter & Value & Unit \\
\hline$L_{b} \times b_{b} \times t_{b}$ & $\begin{array}{c}\text { Geometric size } \\
\text { of the host beam }\end{array}$ & $708 \times 125 \times 2$ & $\mathrm{~mm}$ \\
\hline$L_{p} \times b_{p} \times t_{p}$ & $\begin{array}{c}\text { Geometric size } \\
\text { of the PZT Patch }\end{array}$ & $50 \times 15 \times 1$ & $\mathrm{~mm}$ \\
\hline$\rho_{b}$ & Density of the beam & 1840 & $\mathrm{~kg} / \mathrm{m}^{3}$ \\
\hline$\rho_{p}$ & Density of the PZT patch & 7650 & $\mathrm{~kg} / \mathrm{m}^{3}$ \\
\hline$E_{b}$ & $\begin{array}{c}\text { Elastic modulus } \\
\text { of the beam }\end{array}$ & $\mathrm{GPa}$ \\
\hline$E_{p e}$ & $\begin{array}{c}\text { PZT patch's } \\
\text { elastic modulus }\end{array}$ & 64.64 & $\mathrm{GPa}$ \\
\hline$\nu_{b}$ & Poisson ratio & 0.30 & \\
\hline$\nu_{p}$ & Poisson ratio & 0.30 & $\mathrm{~m} / \mathrm{V}$ \\
\hline$d_{31}$ & $\begin{array}{c}\text { Piezoelectric } \\
\text { strain coefficient }\end{array}$ & $-166 \times 10^{-12}$ & \\
\hline
\end{tabular}




\section{Table 2. Parameters of the pneumatic drive system.}

\begin{tabular}{|c|c|c|c||}
\hline Symbol & Parameter & Value & Unit \\
\hline$A$ & Area of piston & $4.9087 \times 10^{-4}$ & $\mathrm{~m}^{2}$ \\
\hline$D$ & Diameter of piston & 25 & $\mathrm{~mm}$ \\
\hline$d_{c}$ & $\begin{array}{c}\text { The throttle diameter of } \\
\text { the constant throttle valve }\end{array}$ & 0.79 & $\mathrm{~mm}$ \\
\hline$L_{s}$ & $\begin{array}{c}\text { Stroke length } \\
\text { of the rodless cylinder }\end{array}$ & 600 & $\mathrm{~mm}$ \\
\hline$m_{b}$ & $\begin{array}{c}\text { Total mass of the piston } \\
\text { and added inertial loads }\end{array}$ & 2.81 & $\mathrm{~kg}$ \\
\hline$m_{t}$ & $\begin{array}{c}\text { Concentrated mass } \\
\text { of the tip accelerometer }\end{array}$ & 35 & $\mathrm{~g}$ \\
\hline$P_{S 1}$ & $\begin{array}{c}\text { Supply pressure } \\
\text { of left chamber }\end{array}$ & $5 \times 10^{5}$ & $\mathrm{~Pa}$ \\
\hline$P_{S 2}$ & $\begin{array}{c}\text { Supply pressure } \\
\text { of right chamber }\end{array}$ & $5 \times 10^{5}$ & $\mathrm{~Pa}$ \\
\hline$P_{S 0}$ & Back pressure & $3 \times 10^{5}$ & $\mathrm{~Pa}$ \\
\hline$P_{e}$ & Exhaust pressure & $1.013 \times 10^{5}$ & $\mathrm{~Pa}$ \\
\hline$R$ & Gas constant & 287 & $\mathrm{~N} \cdot \mathrm{m} /(\mathrm{kg} \cdot \mathrm{K})$ \\
\hline$K_{q}$ & Gain of charge amplifier & $1.0811 \times 10^{7}$ & $\mathrm{~V} / \mathrm{C}$ \\
\hline
\end{tabular}

tivity is specified as $333 \mathrm{pC} / \mathrm{Unit}$. A signal generator (SPF05) generates the swept sine (chirp) signal and the sine signal for resonant vibration excitation in the experiments. The flexible beam's material is fiberglass colophony. The properties and sizes of the beam/PZT patch and pneumatic system are listed in Table 1 and Table 2 , respectively.

\subsection{System Model}

For modelling of the pneumatic drive piezoelectric flexible beam system, the previous work ${ }^{10}$ has been discussed in detail. The main difference is that the proportional valve is used instead of the PCM valve. The flexural displacement $w(x, t)$ of the flexible beam at point $P(x, t)$ is:

$$
w(x, t)=\sum_{i=1}^{n \rightarrow \infty} \phi_{i}(x) q_{i}(t)
$$

where $q_{i}(t)$ and $\phi_{i}(x)$ are the $i$ th generalized modal coordinate and mode-shape function, respectively.

The PZT sensor measured vibration signal is:

$$
\begin{aligned}
& V_{\mathrm{s}}(t)= \\
& \quad K_{\mathrm{q}} b_{\mathrm{p}} d_{31} E_{\mathrm{pe}}\left(\frac{t_{\mathrm{b}}}{2}+t_{\mathrm{p}}\right) \sum_{i=1}^{n \rightarrow \infty}\left[{\phi^{\prime}}_{i}\left(l_{1}\right)-\phi^{\prime}{ }_{i}\left(l_{2}\right)\right] q_{i}(t)
\end{aligned}
$$

where $K_{q}$ is the charge amplifier coefficient; the primes denote the partial derivative with respect to the variable $x$. The pneumatic cylinder's driving force $F(t)$ is expressed as:

$$
F(t)= \begin{cases}\left(P_{1}(t)-P_{2}(t)\right) A-v_{\mathrm{c}} \dot{y}(t), & \text { if } y(t)>0 \\ \left(P_{2}(t)-P_{1}(t)\right) A-v_{\mathrm{c}} \dot{y}(t), & \text { if } y(t)<0\end{cases}
$$

where $v_{c}$ is the viscous frictional coefficient of the moving pair of the pneumatic cylinder.

The system dynamics of the pneumatic drive flexible beam is:

$$
\begin{aligned}
& \left(m_{\mathrm{b}}+\rho_{\mathrm{b}} A_{\mathrm{b}} L_{\mathrm{b}}+m_{\mathrm{t}}\right) \ddot{y}(t)+v_{\mathrm{c}} \dot{y}(t) \\
+ & \sum_{i=1}^{n \rightarrow \infty}\left[\rho_{\mathrm{b}} A_{\mathrm{b}} \int_{0}^{L_{\mathrm{b}}} \phi_{i}(x) \mathrm{d} x+m_{\mathrm{t}} \phi_{i}\left(L_{\mathrm{t}}\right)\right] \ddot{q}_{i}(t)=F(t) .
\end{aligned}
$$

The piezoelectric driving equation of the $i$ th mode of vibration is:

$$
\begin{aligned}
{\left[\rho_{\mathrm{b}} A_{\mathrm{b}}\right.} & \left.\int_{0}^{L_{\mathrm{b}}} \phi_{i}(x) \mathrm{d} x\right] \ddot{y}(t) \\
& +\rho_{\mathrm{b}} A_{\mathrm{b}} \ddot{q}_{i}(t)+v_{\mathrm{s} i} \dot{q}_{i}(t)+\rho_{\mathrm{b}} A_{\mathrm{b}} \omega_{i}^{2} q_{i}(t)= \\
& \frac{1}{2} E_{\mathrm{pe}} b_{\mathrm{p}} d_{31}\left(t_{\mathrm{p}}+t_{\mathrm{b}}\right)\left[\phi^{\prime}{ }_{i}\left(l_{4}\right)-\phi_{i}{ }^{\prime}\left(l_{3}\right)\right] V_{\mathrm{a}}(t) ;
\end{aligned}
$$

where $V_{a}(t)$ is the applied voltage; $v_{s i}$ is the $i$ th modal structural damping ratio.

\section{CONTROLLER DESIGN}

The central objective of set-point vibration suppression is to maintain the slider at its specified position as the time scale ends, and cause the residual vibration to damp out quickly. The purpose of the resonant vibration control is to significantly suppress the resonant vibration, which is under first excitation using the PZT actuator, from large amplitude to low amplitude. An adaptive fuzzy sliding mode controller is investigated, and a composite PD controller is utilized for comparison.

\subsection{PD Control}

The measured displacement and vibration signals are treated as feedback information. Both pneumatic rodless cylinder and PZT actuator can be used as actuators to suppress the vibration of the flexible beam. Similar to the previous work, ${ }^{10}$ three PD controllers are designed and expressed as:

$$
\left\{\begin{array}{l}
u_{\mathrm{pn}}(t)=K_{\mathrm{p} 1}\left[y_{\mathrm{d}}-y(t)\right]-K_{\mathrm{d} 1} \dot{y}(t)-K_{\mathrm{p} 2} V_{s}(t)-K_{\mathrm{d} 2} \dot{V}_{s}(t) \\
u_{\mathrm{pe}}(t)=-K_{\mathrm{p} 3} V_{s}(t)-K_{\mathrm{d} 3} \dot{V}_{s}(t)
\end{array} ;\right.
$$

where $u_{p n}(t)$ denotes the control voltage applied to the pneumatic proportional valve; $u_{p e}(t)$ is the control voltage applied to the PZT actuator; $K_{p 1}<0$ and $K_{d 1}>0$ are PD control gains for positioning control of the slider; $K_{p 2}>0$ and $K_{d 2}>0$ are PD control gains for controlling the flexible beam's vibration by employing the rodless cylinder; $K_{p 3}>0$ and $K_{d 3}>0$ are PD control gains for attenuating the flexible beam's vibration by utilizing the PZT actuator; and $y_{d}$ is the slider's desired position.

The control bandwidth of this pneumatic system is lower than the modal frequency of the second vibration mode. Therefore, only the first modal large amplitude vibration can be effectively controlled by the pneumatic cylinder. The small amplitude vibration of the first mode and the vibration of the second mode should be controlled only by using the PZT actuator.

\subsection{Adaptive Fuzzy Sliding Mode Control}

AFSMC is adopted and incorporated with the pneumatic drive piezoelectric flexible beam system. The AFSMC is directly cited from corresponding adaptive fuzzy sliding-mode control references. ${ }^{7,8,11-13}$

Consider a nonlinear system is written as

$$
x^{(n)}=f(\mathbf{x})+u
$$

where $\mathbf{x}=\left(x, \dot{x}, \cdots, x^{(n-1)}\right)^{T} \in R^{n}$ is the state vector; $u \in R$ is the input; $f(x)$ is a nonlinear function. The control objective is to make the state $\mathbf{x}$ for tracking a desired 


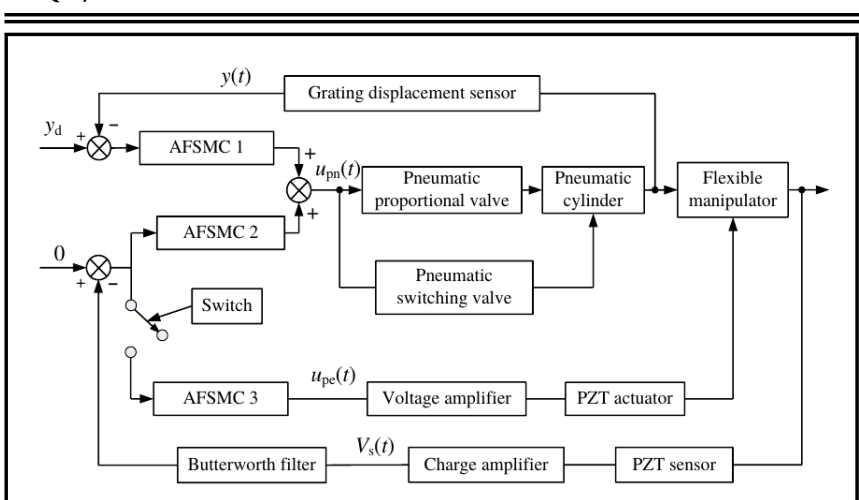

(a) Block diagram of the control system of the adaptive fuzzy sliding mode control.

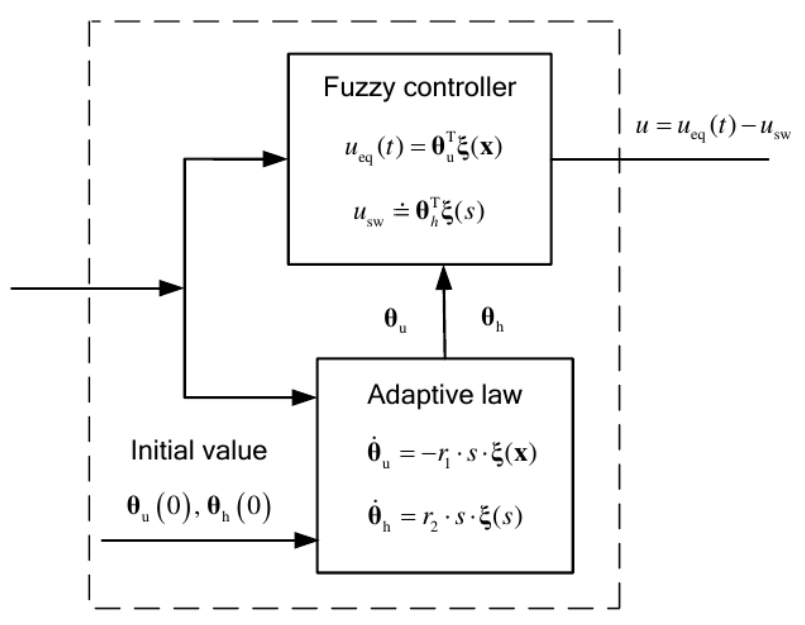

(b) Adaptive fuzzy sliding mode control.

Figure 5. Block diagram of the controllers' structure.

state $\mathbf{x}_{d}=\left(x_{d}, \dot{x}_{d}, \cdots, x_{d}^{(n-1)}\right)^{T}$. The tracking error is $\mathbf{e}=\mathbf{x}-\mathbf{x}_{d}=\left(e, \dot{e}, \cdots, e^{(n-1)}\right)^{T}$. Then a sliding surface is defined as:

$$
s(x, t)=-\left(k_{1} e+k_{2} \dot{e}+\cdots+k_{n-1} e^{(n-2)}+e^{(n-1)}\right) ;
$$

where $\mathbf{k}=\left(k_{1}, k_{2}, \cdots, k_{n-1}, 1\right)$ are the coefficients of the Hurwitzian polynomial $\lambda^{n-1}+k_{n-1} \lambda^{n-2}+\cdots k_{2} \lambda+k_{1}$, which guarantee all the solutions of the equation $\lambda^{n-1}+$ $k_{n-1} \lambda^{n-2}+\cdots k_{2} \lambda+k_{1}=0$ to be in the left half of the plane.

A stable condition is $s(x, t) \cdot \dot{s}(x, t) \leq-\eta|s|$, where $\eta>0$. The control law becomes:

$$
u=u_{\mathrm{eq}}-u_{\mathrm{sw}}
$$

where $u_{e q}$ is the equivalent controller; $u_{s w}$ is a switching-type control term.

The switching-type control is expressed as:

$$
u_{\mathrm{sw}}=\eta_{\Delta} \operatorname{sgn}(s)
$$

where $\eta_{\Delta}=\left|u_{\mathrm{sw}}\right|, \eta_{\Delta} \geq \eta>0$.

The fuzzy system is characterized by a set of if-then rules in the following form:

$$
R^{j}: \text { If } x_{1} \text { is } F_{1}^{j} \text {, and } x_{2} \text { is } F_{2}^{j}, \cdots \text {, and } x_{m} \text { is } F_{m}^{j} \text {, }
$$

then $u$ is $B^{j}$; where $F_{i}^{j}\left(i=1,2, \cdots, m ; j=1,2, \cdots, N_{i}\right.$, where $N_{i}$ is the number of rules) and $B^{j}$ are fuzzy sets defined on $R$, and $N=\prod_{i=1}^{m} N_{i}$ is the total number of rules.

The equivalent controller is:

$$
u_{\mathrm{eq}}=\theta_{\mathrm{u}}^{\mathrm{T}} \xi(\mathbf{x})
$$

where $\theta_{\mathrm{u}}=\left(\theta_{1}, \cdots, \theta_{m}\right)^{\mathrm{T}}$ is a set of adjustable consequent parameters; $\xi(\mathbf{x})=\left(\xi_{1}(\mathbf{x}), \cdots, \xi_{m}(\mathbf{x})\right)^{\mathrm{T}}$ is a set of fuzzy basis functions, and $\xi_{i}(\mathbf{x})$ is defined as: $:^{13}$

$$
\xi_{i}(\mathbf{x})=\frac{\prod_{j=1}^{n} \mu_{F_{j}^{i}}\left(x_{j}\right)}{\sum_{i=1}^{m} \prod_{j=1}^{n} \mu_{F_{j}^{i}}\left(x_{j}\right)}, \quad i=1,2, \cdots, m
$$

where $\mu_{F_{j}^{i}}\left(x_{j}\right)$ is the membership function of the fuzzy controller; $n$ is the number of the input fuzzy controllers; and $m$ is the number of the fuzzy rules.

The switching-type control term $u_{s w}$ is approximately expressed as:

$$
u_{\mathrm{sw}}=\hat{h}\left(s / \theta_{h}\right)=\theta_{h}^{\mathrm{T}} \xi(s) .
$$

The parameter update law is:

$$
\begin{gathered}
\dot{\theta}_{\mathrm{u}}=-r_{1} \cdot s \cdot \xi(\mathbf{x}) ; \\
\dot{\theta}_{\mathrm{h}}=r_{2} \cdot s \cdot \xi(s) ;
\end{gathered}
$$

where $r_{1}$ and $r_{2}$ are the positive constants.

The block diagram for the control structure of the adaptive fuzzy sliding mode control is shown in Fig. 5(a). The control voltage $u_{p n}(t)$ applied to the proportional valve is composed of two AFSMC components: AFSMC 1 for positioning the slider and AFSMC 2 for suppressing the large amplitude vibration of the first mode. On account of the limited bandwidth of the pneumatic rodless cylinder, the PZT patch actuator is also utilized to damp out the residual vibration of the first two modes. The control action of $u_{p e}(t)$ is applied to the PZT actuator, comprising one adaptive fuzzy sliding mode control of AFSMC 3 . The block diagram of the mentioned three AFSMCs is shown in Fig. 5(b). The parameters used for designing the controllers should be provided beforehand, such as the initial value of $\theta_{u}(0)$ and $\theta_{h}(0)$. The learning rates used in the adaptive fuzzy sliding mode control are chosen as: $r_{1}=0.4$ and $r_{2}=0.1$ The initial parameter is chosen as $\theta_{i}(0)=0$. The membership functions for $x_{i}$ are given as: $\mu_{F_{i}^{1}}\left(x_{i}\right)=$ $1 /\left[1+\exp \left(10.0\left(x_{i}+2.5\right)\right)\right], \mu_{F_{i}^{2}}\left(x_{i}\right)=\exp \left[-5.0\left(x_{i}+2.4\right)^{2}\right]$, $\mu_{F_{i}^{3}}\left(x_{i}\right)=\exp \left[-5.0\left(x_{i}+1.8\right)^{2}\right], \quad \mu_{F_{i}^{4}}\left(x_{i}\right)=$ $\exp \left[-5.0\left(x_{i}+1.2\right)^{2}\right], \quad \mu_{F_{i}^{5}}\left(x_{i}\right)=\exp \left[-5.0\left(x_{i}+0.6\right)^{2}\right]$, $\mu_{F_{i}^{6}}\left(x_{i}\right)=\exp \left[-5.0 x_{i}^{2}\right], \mu_{F_{i}^{7}}\left(x_{i}\right)=\exp \left[-5.0\left(x_{i}-0.6\right)^{2}\right]$, $\mu_{F_{i}^{8}}\left(x_{i}\right)=\exp \left[-5.0\left(x_{i}-1.2\right)^{2}\right], \quad \mu_{F_{i}^{9}}\left(x_{i}\right)=$ $\exp \left[-5.0\left(x_{i}-1.8\right)^{2}\right], \quad \mu_{F_{i}^{10}}\left(x_{i}\right)=\exp \left[-5.0\left(x_{i}-2.4\right)^{2}\right]$, $\mu_{F_{i}^{11}}\left(x_{i}\right)=1 /\left[1+\exp \left(10.0\left(x_{i}-2.5\right)\right)\right]$.

Since the long stroke of the rodless cylinder and large compressibility of air, the hysteresis problem will emerge. If the control hysteresis is not compensated effectively, the control performance and the stability of the closed-loop system will be affected. Therefore, a time delay compensator is employed to deal with the problem of hysteresis, by applying phase shifting methods. In addition, the high frequency noises will cause control spill over. To filter out the high frequency noises of the measured signal, the Butterworth notch filter and low-pass filter are designed and used in the experiments. 


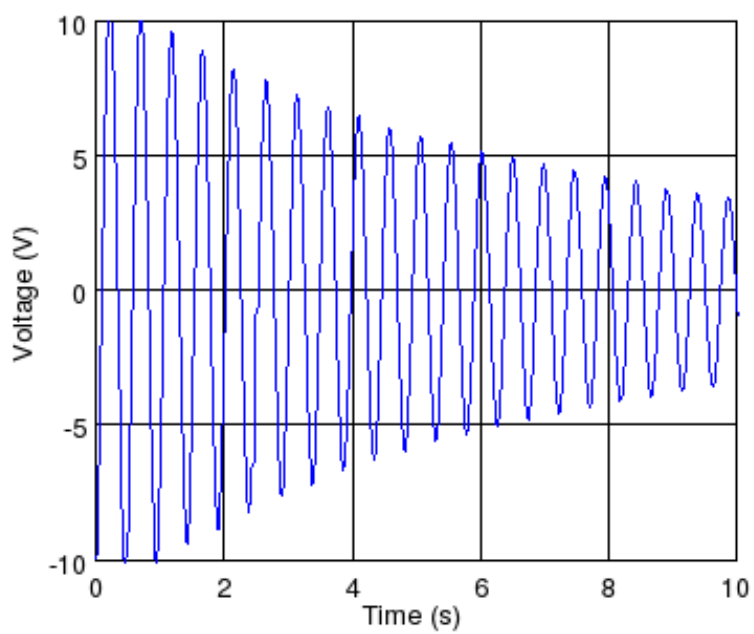

(a) Time-domain vibration response.

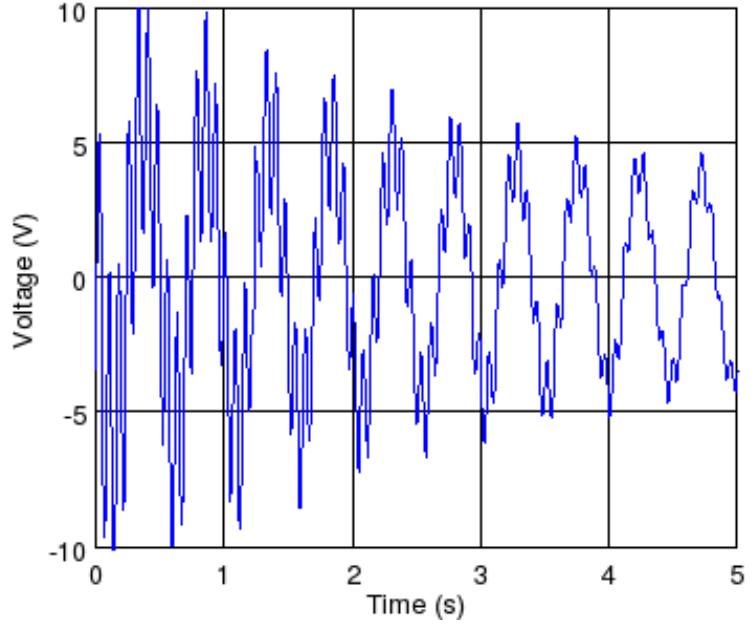

(c) Time-domain vibration response.

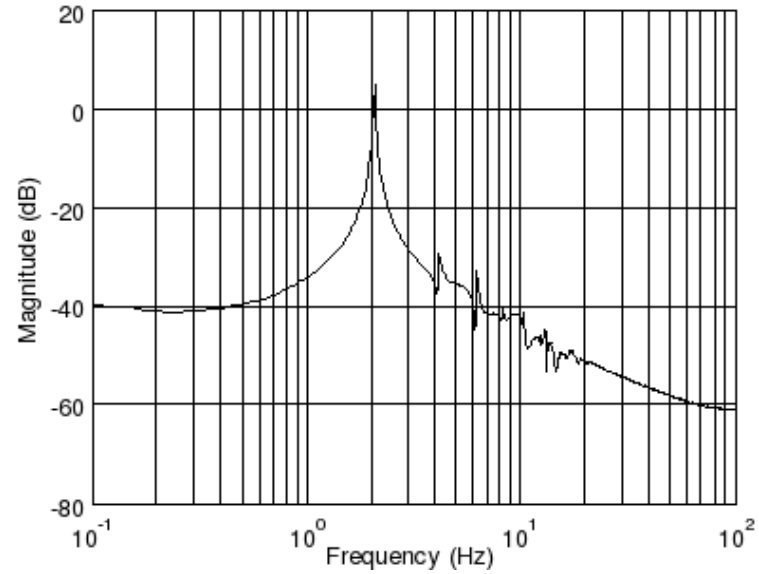

(b) Frequency response.

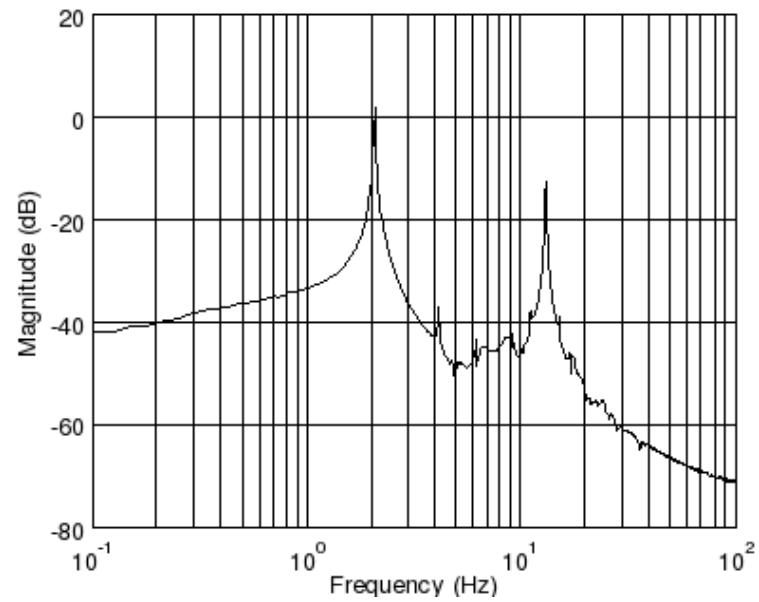

(d) Frequency response.

Figure 6. Free vibration responses of the first and the first two bending modes

\section{EXPERIMENTAL RESULTS}

The presented experimental results include: modal identification of the natural frequencies, set-point vibration suppression only employing the pneumatic cylinder, set-point vibration control using both pneumatic cylinder and PZT actuator, and resonant vibration suppression under persistent excitation. The sampling interval is specified as $5 \mathrm{~ms}$.

Two controllers are compared, namely, the composite PD controller and the adaptive fuzzy slide sliding controller. The control action is applied at the moment of $t=1.0 \mathrm{~s}$. The corresponding control parameters are selected after testing experiments.

The proportional valve is stopped when the control value enters the specified bound for lasting the specified time. After several tests, the bound is selected as $0.6 \mathrm{~V}$ and the specified time is chosen as 50 sampling periods. This will not excite the limit cycle oscillation because of the nonlinear properties of the pneumatic system. Remarks: In the subsequent experimental results, the curves of the control voltages applied to the proportional valve can be positive and negative, with their ranges of $-5 \mathrm{~V} \sim+5 \mathrm{~V}$. The positive or negative value can be realized by switching on or switching off the 5-2 way switching solenoid valve. The positive value is the case that the 5-2 way switching solenoid valve is in the left position, while the nega- tive value is the case in the right position. The practical control voltage applied to the proportional valve is the absolute values of the signals plotted on the experimental curves.

\subsection{Experimental Identification}

When the slider of the pneumatic cylinder stops at some point, the flexible manipulator is approximately considered as a clamped beam with a concentrated tip mass. The friction force of the cylinder's prismatic pair can keep the slider stationary without pneumatic drive. Excitation analyses are conducted to identify the natural frequencies.

For experimental identification, impulse excitation was applied. To obtain the first bending mode of vibration, the tip of the beam was pushed to a distance, and then the free vibration of the first mode was caused. To obtain the vibration of the first two modes, the flexible beam was hit at some certain points by using a hammer.

The measured free vibration of the first and the first two bending modes by the PZT sensor are shown in Fig. 6. Figures 6(a) and 6(b) plot the time-domain response and the frequency response obtained by employing fast Fourier transform (FFT), respectively. Figures 6(c) and 6(d) are the time-domain response and the frequency response obtained by employing FFT, respectively. From Fig. 6(a) and Fig. 6(c), it can be ob- 


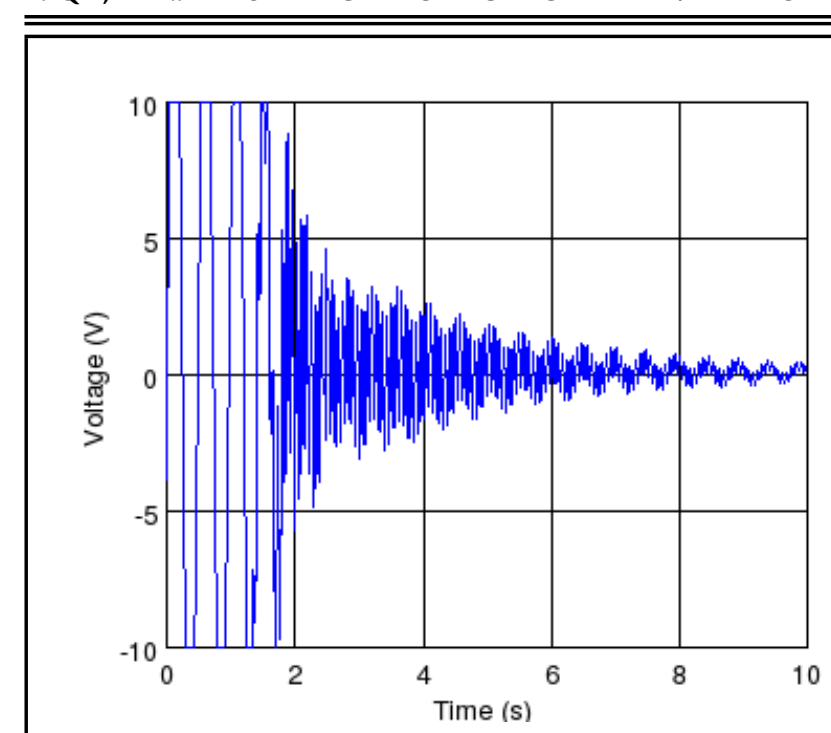

(a) Time-domain vibration response under PD control.

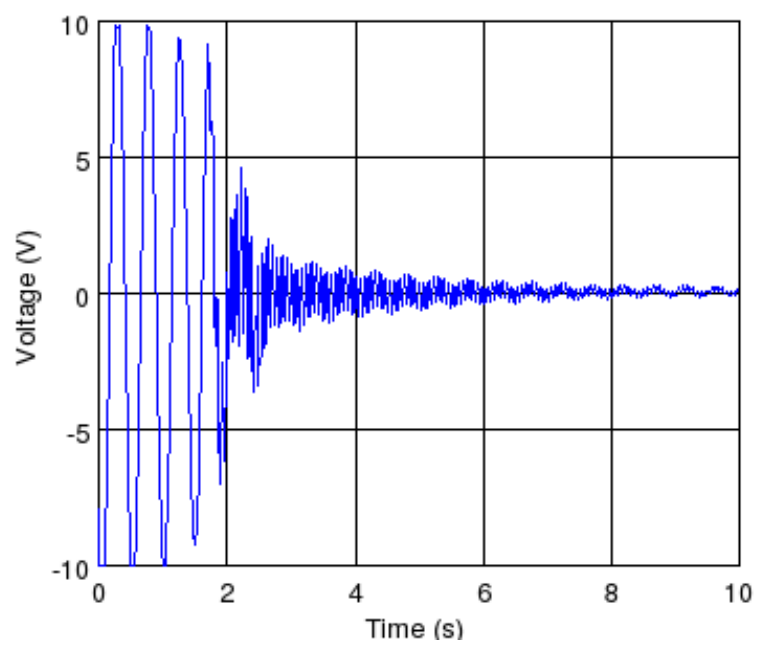

(c) Time-domain vibration response under AFSMC.

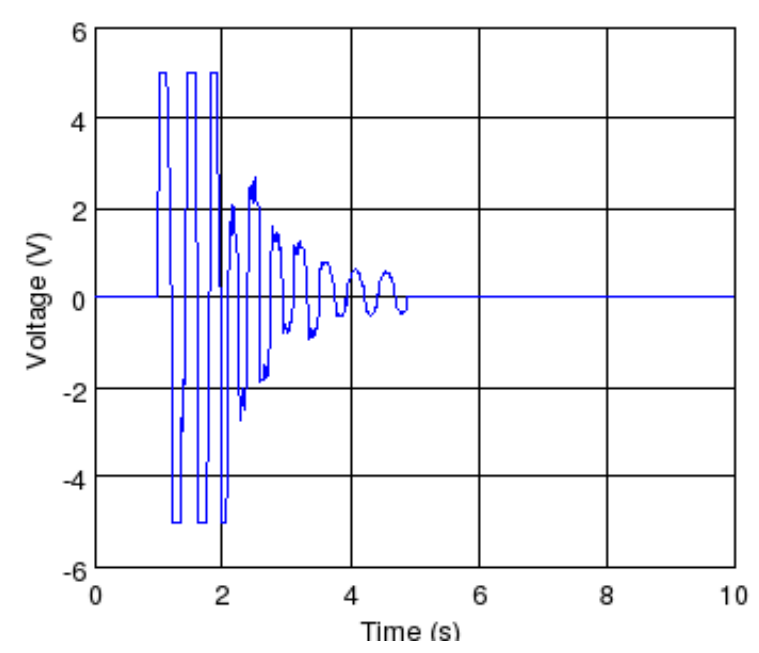

(b) Control voltage applied to the proportional valve.

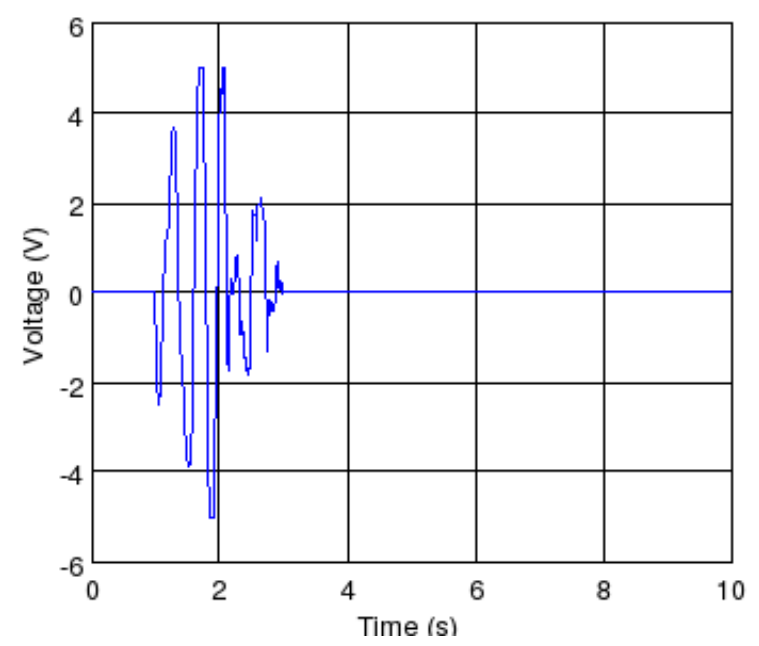

(d) Control voltage applied to the proportional valve.

Figure 7. Set-point vibration suppression using the pneumatic cylinder under PD control and AFSMC.

served that the vibrations will take a long time to decay without introducing active control. Next, from Fig. 6(b) and Fig. 6(d), it can be observed that the identified natural frequencies of the first two modes are $\omega_{1}=2.08 \mathrm{~Hz}$ and $\omega_{2}=13.16 \mathrm{~Hz}$.

\subsection{Set-point Vibration Control Using Only the Rodless Cylinder}

Here, the pneumatic cylinder is employed as the actuator to suppress the vibration. When the vibration of the first mode of the flexible beam is excited, experimental results for vibration control are shown in Fig. 7, utilizing the PD controller and the AFSMC. The control parameters of the PD control are $K_{p 1}=0.3, K_{d 1}=0.008, K_{p 2}=0.25$, and $K_{d 2}=0.05$. Figures 7(a) and 7(c) depict the controlled time-domain vibration response, respectively. Figures 7(b) and 7(d) plot the control voltage applied to the proportional valve, respectively. From Fig. 7(a) and Fig. 7(c), it can be observed that the larger amplitude vibration of the first mode can be suppressed effectively. However, the vibration of the second bending mode gets unavoidably excited in the process of applying control action. This is the phenomenon where the control spills over into the high order mode of vibration when controlling the vibration of the first mode.
Comparing Fig. 7(c) with Fig. 7(a), it can be observed that AFSMC is better than PD control, although the vibration of the flexible beam be cannot be eliminated completely. This results into nonlinear friction of the pair, intrinsic nonlinearity, low stiffness, parametric variations, hysteresis characteristics of the long-stroke pneumatic cylinder, and the hysteresis of the pneumatic servo system caused by the solenoid valves. Because of the bandwidth limitation of the pneumatic control system, the vibration of the second mode cannot be suppressed effectively. Therefore, the PZT actuator should be introduced as the actuator to suppress the vibration of the second mode simultaneously.

From Fig. 7(d) and Fig. 7(b), it can be observed that the control value under PD control reaches saturation abruptly after applying control effect, which is undesirable. It is harmful to actuator devices, and it may cause oscillation of the high frequency mode, while the control voltage of AFSMC increases gradually to saturation. This can weaken the control effect at the beginning, in turn avoiding excitation of the large amplitude oscillations. Comparison of Fig. 7(a) with Fig. 7(c) shows that the amplitude of the oscillation by AFSMC is less than that of the PD controller. 


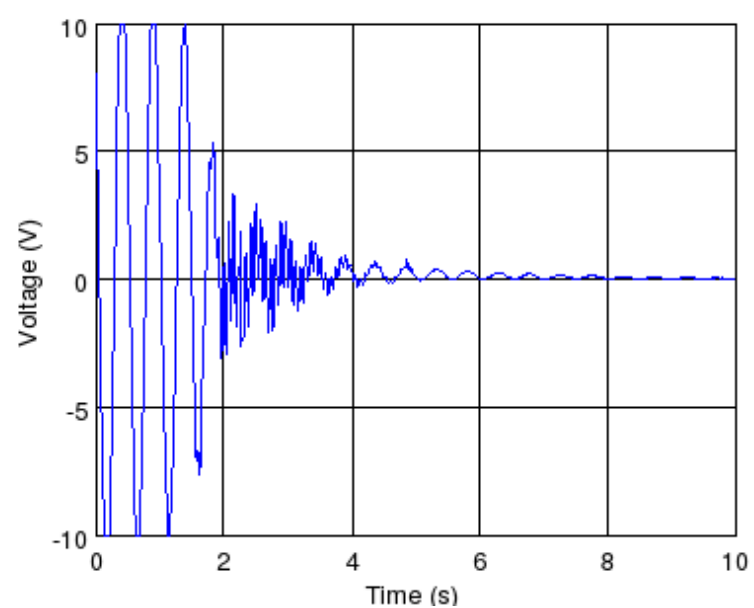

(a) Time-domain vibration response.

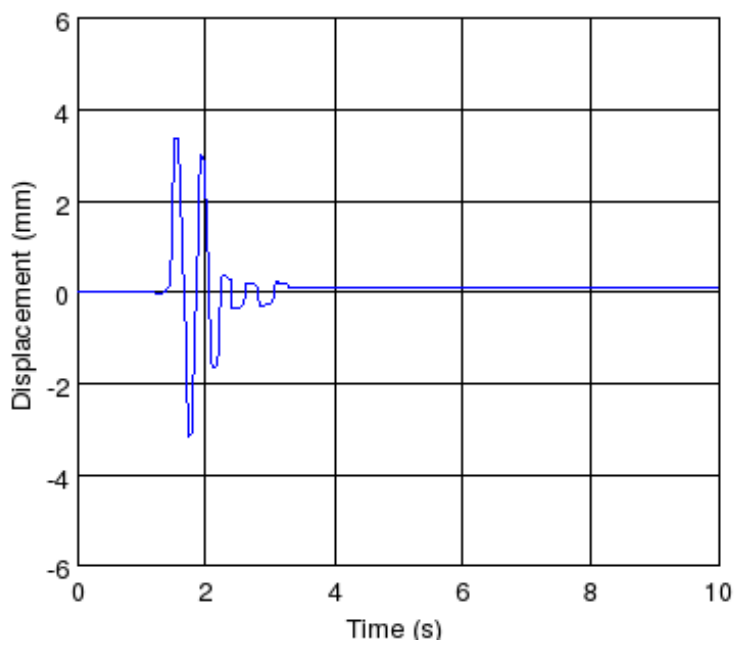

(c) Displacement curve of the slider.

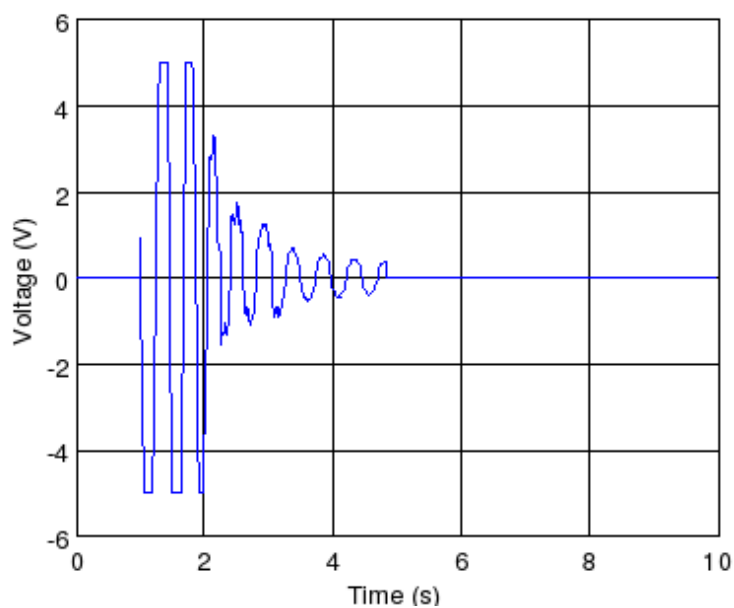

(b) Control voltage applied to the proportional valve.

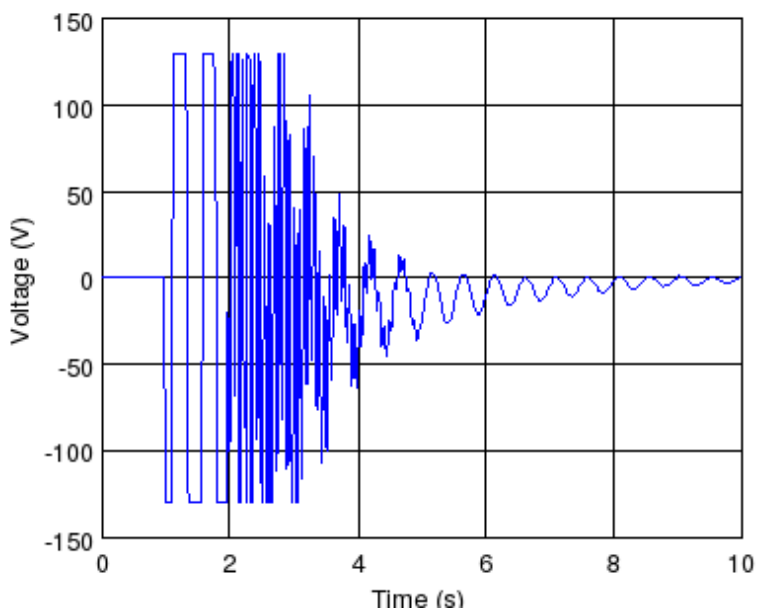

(d) Control voltage applied to the PZT actuator.

Figure 8. Set-point vibration suppression using both pneumatic cylinder and PZT actuator under PD control.

\subsection{Set-point Vibration Control Using Both Pneumatic Cylinder and PZT Actuator}

The excited vibration is desired to be attenuated as quickly as possible. Especially, the small amplitude residual vibration should be damped out thoroughly. Therefore, the hybrid driving scheme is used, i.e., both pneumatic cylinder and PZT actuator are employed to suppress the set-point vibration.

The experimental results of the set-point vibration control using PD control are shown in Fig. 8. The control parameters of the PD control are $K_{p 1}=0.3, K_{d 1}=0.008, K_{p 2}=0.25$, $K_{d 2}=0.05, K_{p 3}=2.5$, and $K_{d 3}=0.02$. The control parameters of the AFSMC method are $\gamma_{1}=0.002$ and $\gamma_{2}=0.0005$.

Figures $8(\mathrm{a}), 8(\mathrm{~b}), 8(\mathrm{c})$, and $8(\mathrm{~d})$ correspond to the timedomain vibration, the control voltage applied to the pneumatic proportional valve, the displacement curve of the slider, and the PZT actuators control voltage, respectively. Figure 9 is the result of the set-point vibration control using AFSMC. Figures 9(a), 9(b), 9(c), and 9(d) show the time-domain controlled vibration response curve, the corresponding control voltage applied to the proportional valve, the displacement curve of the slider, and the PZT actuator's control voltage, respectively. From Fig. 9(a) and Fig. 8(a), it can be observed that the residual vibration disappears as the time scale ends.

From the experimental results, it can be observed that the de- signed AFSMC has several advantages over the PD controller: (1) the vibration is suppressed largely. (2) Since the control voltage applied to the proportional valve does not reach its saturation instantly, the control energy is saved and the stability of the closed-loop system can be guaranteed; furthermore, the high frequency chattering will not be excited greatly. (3) The residual vibration can be effectively damped out by the PZT actuator, and the performance of the AFSMC is better than the PD controller. The composite strategy can suppress both large and small amplitude vibrations effectively.

\subsection{Vibration Control Under Persistent Resonant Excitation}

The signal generator SPF05 generates a sine signal with its frequency of the first bending mode of vibration, i.e., $2.08 \mathrm{~Hz}$. Its amplitude is tuned to an appropriate level. Then, the generated signal is used to excite the flexible beams resonant vibration by the PZT actuator after amplifying with the high voltage amplifier. The control action by the pneumatic rodless cylinder is applied at the moment of $t=1.0 \mathrm{~s}$.

The results of time-domain responses using the PD controller under the first resonant excitation are shown in Fig. 10. Figure 10(a) plots the time-domain vibration response before and after introducing control. Figure 10(b) depicts the control 


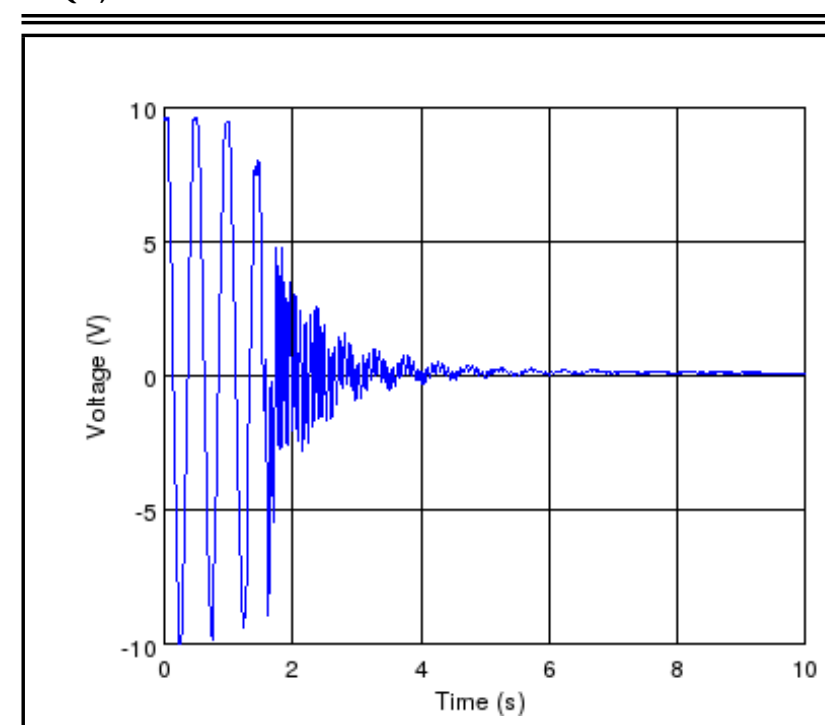

(a) Time-domain vibration response.

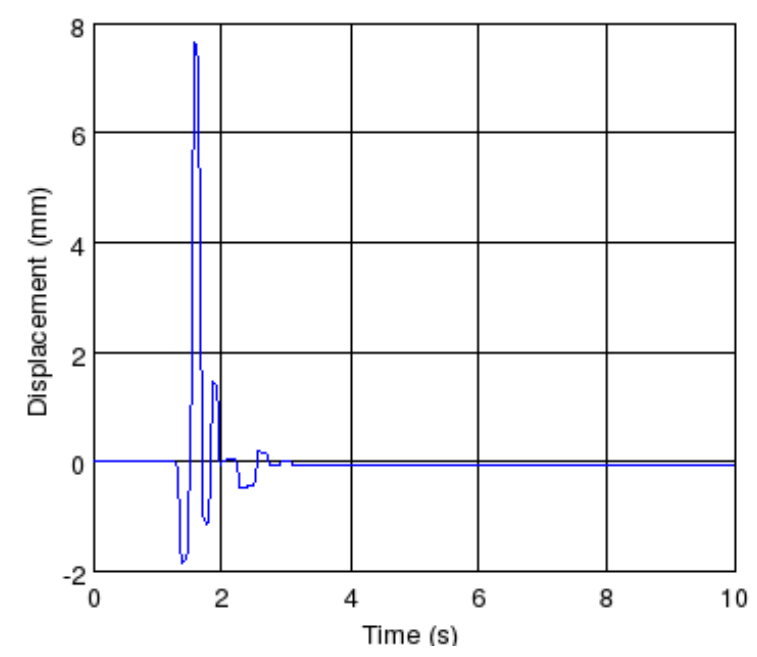

(c) Displacement of the slider.

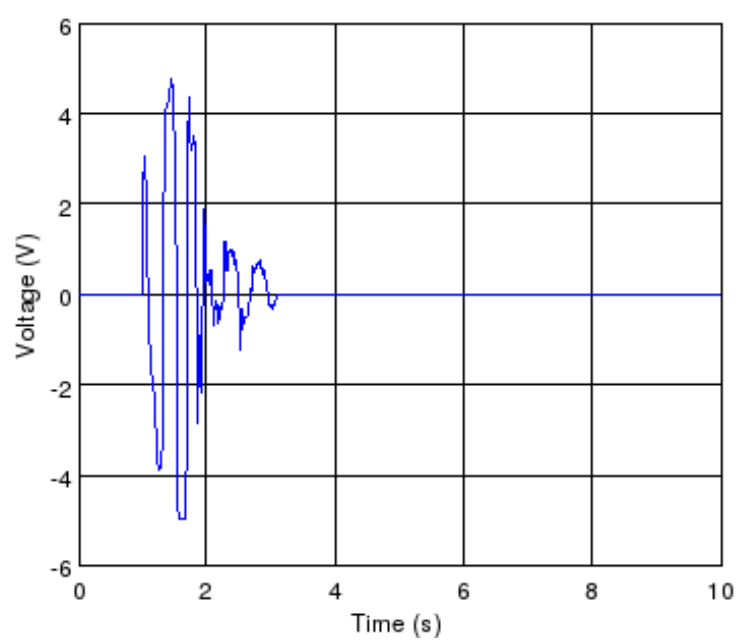

(b) Control voltage applied to the proportional valve.

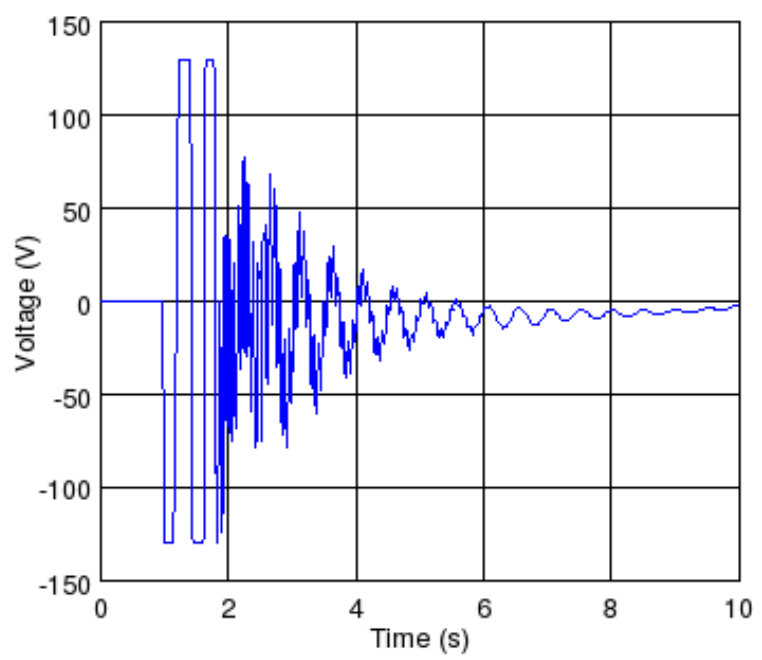

(d) PZT actuator's control voltage.

Figure 9. Set-point vibration suppression using both pneumatic cylinder and PZT actuator under AFSMC.

voltage applied to the proportional valve. Figure 10(c) is the displacement of the slider of the cylinder. Figure 10(d) shows the power spectrum magnitude of the vibration response shown in Fig. 10(a) that is applied control from $t=1.0 \mathrm{~s}$ to the moment of $t=25.0 \mathrm{~s}$. The PSD amplitudes of the first two modes are $31.2 \mathrm{~dB}$ and $17.6 \mathrm{~dB}$.

Figure 11 shows the experimental results on the resonant vibration suppression by using AFSMC. Figures 11(a), 11(b), and 11(c) depict the time-domain vibration response before and after applying control, the control voltage applied to the pneumatic proportional valve, and the slider's displacement, respectively. Figure $11(\mathrm{~d})$ is the power spectrum magnitude of the vibration curve of Fig. 11(a) for control applied from $t=1.0 \mathrm{~s}$ to the moment of $t=25.0 \mathrm{~s}$. The vibration PSD amplitudes of the first two modes are $24.3 \mathrm{~dB}$ and $19.8 \mathrm{~dB}$, respectively. From Fig. 10(a) and Fig. 11(a), it is observed that the vibration amplitude of the first mode is reduced significantly after introducing control by the cylinder. However, those of the second mode are excited. From Fig. 10(d) and Fig. 11(d), it is observed that the PSD magnitude of the first mode of vibration is decreased by using AFSMC as compared with the PD controller, while that of the second mode is increased a little. This is because the AFSMC is a kind of nonlinear control algorithm, which will excite the vibration of the second mode.
Further, the goal of suppressing the vibration of the first mode can be achieved.

From Fig. 10(c) and Fig. 11(c), it can be observed that the slider's oscillations around the equilibrium point will be caused, as the boundary control effect suppresses the resonant vibration under the first persistent excitation, corresponding to the control voltage applied to the proportional valve shown in Fig. 10(b) and Fig. 11(b).

Comparing Fig. 11(d) with Fig. 10(d), it can be observed that the control value of the AFSMC does not reach saturation immediately when the control effect is applied to the large amplitude vibration; however, that of the PD controller reaches saturation instantly for the large amplitude vibration suppression action. This is just what we expect not to affect the stability of the closed-loop control system. The second frequency mode is higher when compared to PD controller. This is the reason why AFSMC is a kind of nonlinear control method. It will excite the high frequency mode vibration a little larger.

From the experiments, it is observed that the dynamic characteristic of the pneumatic drive flexible beam system is complicated. The designed controllers can obtain satisfactory control effect, for residual vibration suppression and resonant vibration control. The control performance of the designed AFSMC is better than the PD controller. 


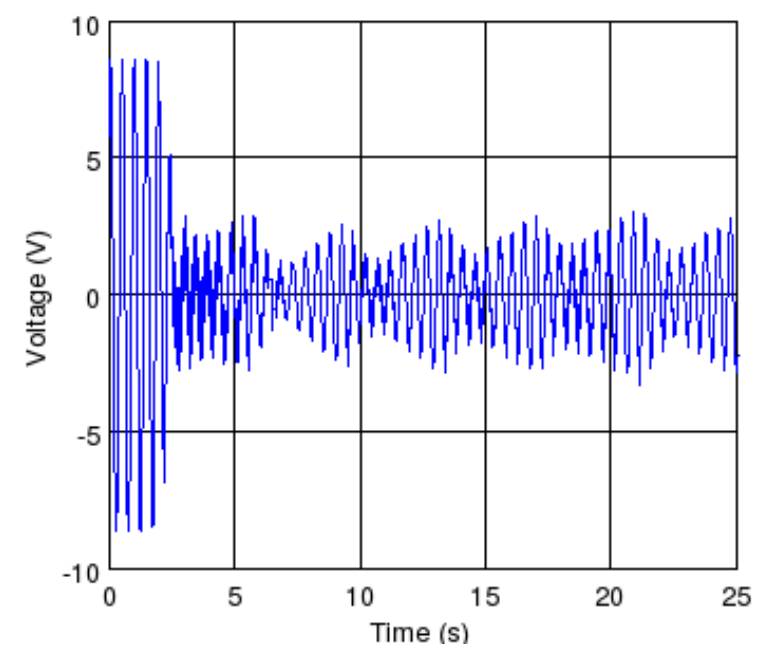

(a) Time-domain vibration response.

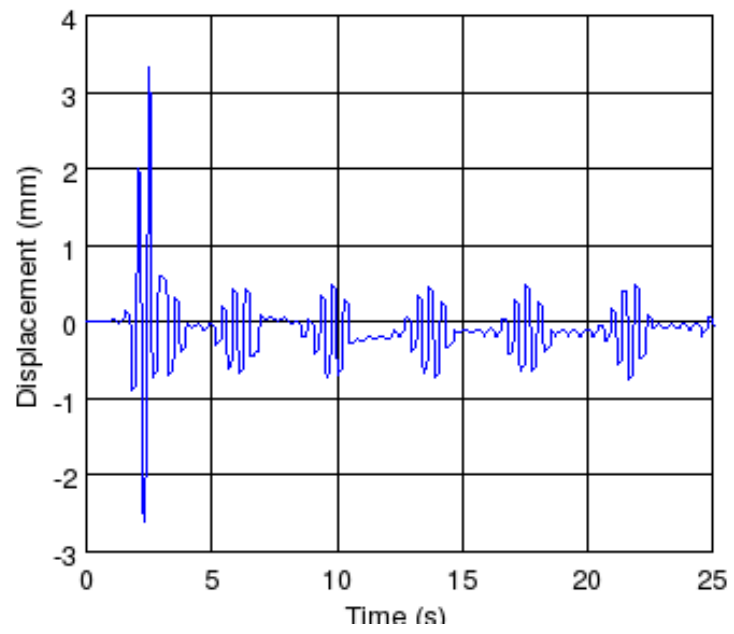

(c) Displacement of the slider.

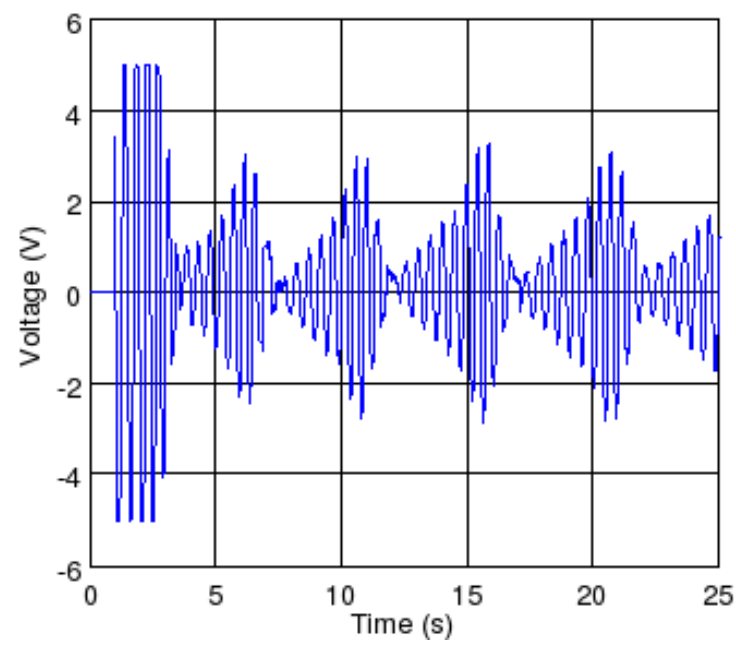

(b) Control voltage applied to the proportional valve.

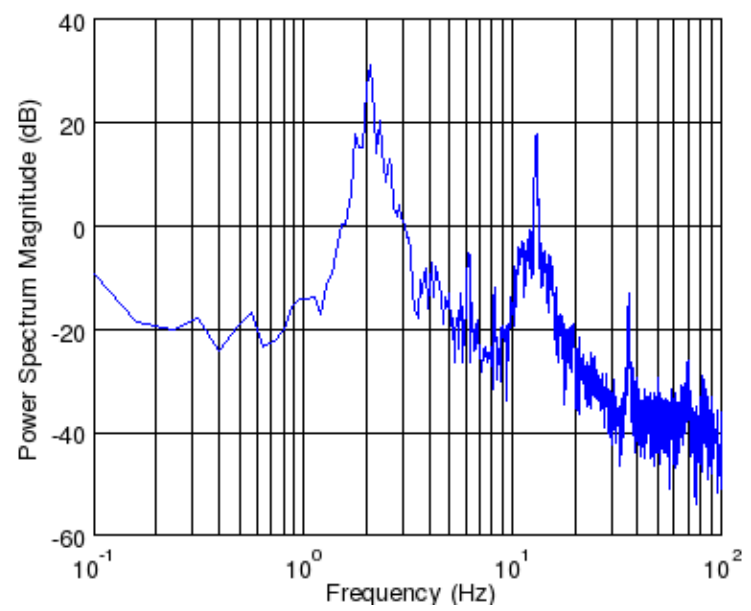

(d) Power spectrum magnitude of the vibration response.

Figure 10. Time-domain vibration responses using the PD controller under the first resonant excitation.

\section{CONCLUSION}

A pneumatic rodless cylinder that drives a translating flexible piezoelectric beam system is constructed. A pneumatic proportional valve is used. The classical PD control and the adaptive fuzzy sliding mode controller are designed and applied to control the proposed system. Experiments are presented including modal frequency identification, residual vibration suppression and resonant vibration control under excitation of the first mode. Comparisons of the two controllers are discussed. The experimental results demonstrate that the proposed pneumatic drive flexible beam system can effectively attenuate the vibration, by metering the exhaust air flow with the proportional valve. Moreover, the designed AFSMC enhances the performance.

\section{ACKNOWLEDGEMENTS}

This work was in par supported by the National Natural Science Foundation of China under Grant 51175181, in part supported by the Fundamental Research Funds for the Central Universities, SCUT (2014ZG0019), partially supported by The Natural Science Foundation of Guangdong Province (S2013030013355) and partially supported by the State Key Laboratory of Robotics Foundation. The first author gratefully acknowledges those agencies.

\section{REFERENCES}

1 Hodgson S., Le M. Q., Tavakoli M., Pham M. T. Improved tracking and switching performance of an electro-pneumatic positioning system. Mechatronics, 22 (1), 1-12, (2012). https://dx.doi.org/10.1016/j.mechatronics.2011.10.007

2 Schulte H. and Hahn H. Fuzzy state feedback gain scheduling control of servo-pneumatic actuators. Control Engineering Practice 12 (5), 639-650, (2004). https://dx.doi.org/10.1016/S0967-0661(03)00148-5

3 Kaitwanidvilai S. and Olranthichachat P. Robust loop shaping fuzzy gain scheduling control of a servopneumatic system using particle swarm optimization approach. Mechatronics 21 (1), 11-21, (2011). https://dx.doi.org/10.1016/j.mechatronics.2010.07.010

4 Chen Y., Zhang J. F., Yang C. J., and Niu B. Design and hybrid control of the pneumatic forcefeedback systems for Arm-Exoskeleton by using on/off valve. Mechatronics 17 (6), 325-335, (2007). https://dx.doi.org/10.1016/j.mechatronics.2007.04.001 


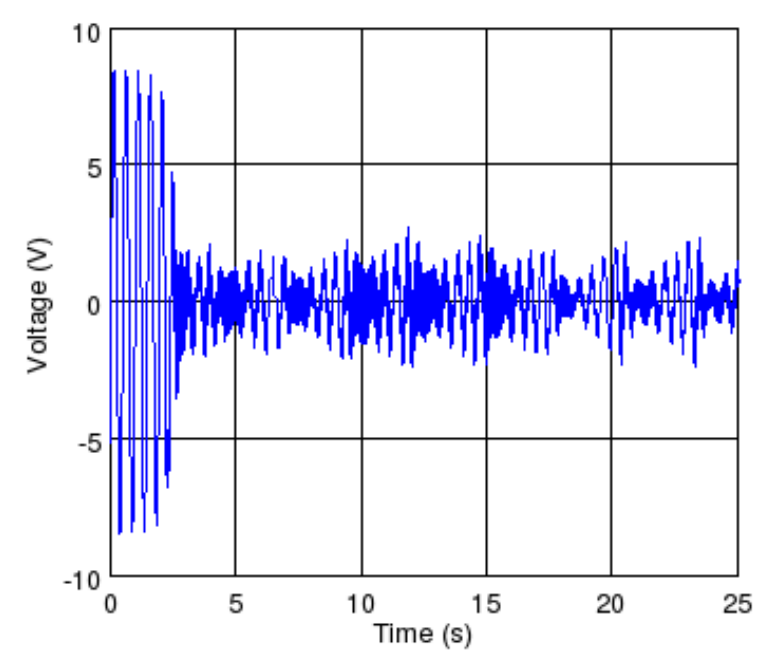

(a) Time-domain vibration response.

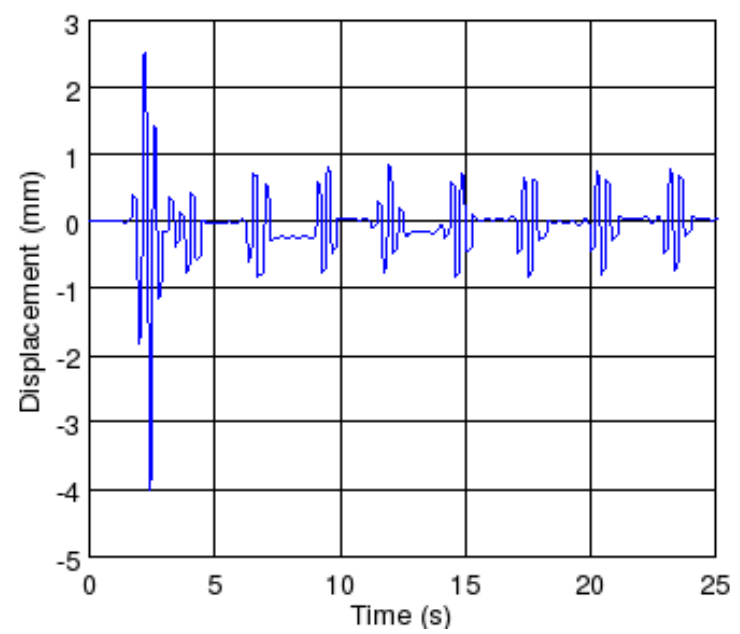

(c) Displacement curve of the slider.

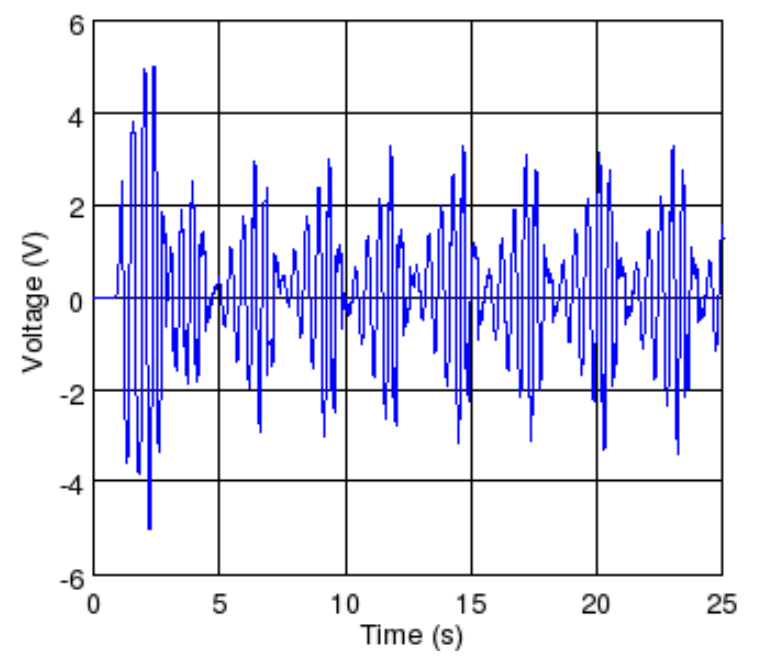

(b) Control voltage applied to the proportional valve.

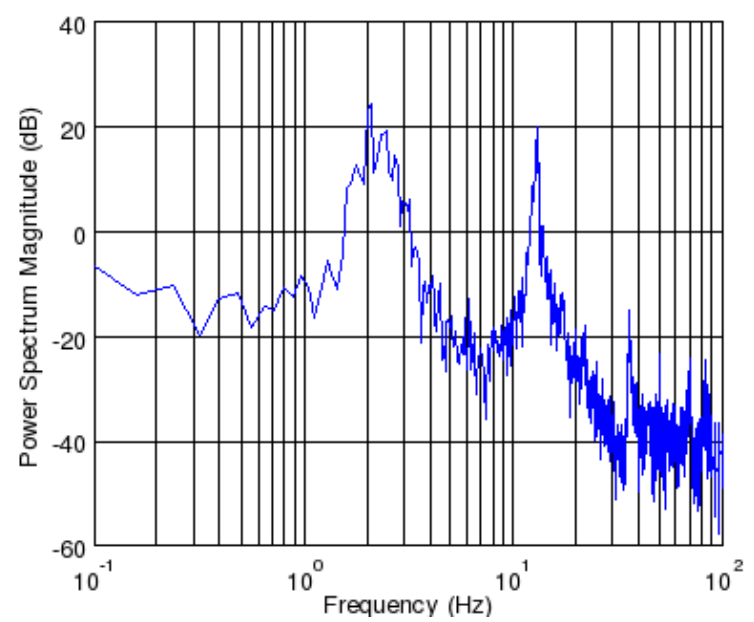

(d) Power spectrum magnitude of the vibration response.

Figure 11. Time-domain vibration responses using the AFSMC under the first resonant excitation.

5 Chiang M. H., Chen C. C., and Tsou T. N. Large stroke and high precision pneumatic-piezoelectric hybrid positioning control using adaptive discrete variable structure control. Mechatronics 15 (5), 523545, (2005). https://dx.doi.org/10.1016/j.mechatronics.2004.11.003

6 Tsai Y. C. and Huang A. C. Multiple-surface sliding controller design for pneumatic servo system. Mechatronics 18 (9), 506-512, (2008). https://dx.doi.org/10.1016/j.mechatronics.2008.03.006

7 Lu Q., Peng Z. K., Chu F. L., and Huang J. Y. Active vibration control using direct adaptive fuzzy sliding mode controller. Chinese Journal of Mechanical Engineering 40 (1), 90-94, (2004), (In Chinese).

${ }^{8}$ Ho T. H. and Ahn K. K. Speed control of a hydraulic pressure coupling drive using an adaptive fuzzy sliding-mode control. IEEE/ASME Transactions on Mechatronics 15 (5), 976-986, (2012). https://dx.doi.org/10.1109/TMECH.2011.2153866

9 Phu D. X., Quoc N. V., Park J. H., and Choi S. B. Design of a novel adaptive fuzzy sliding mode controller and application for vibration control of magne- torheological mount, Proc IMechE Part C: J Mechanical Engineering Science, 228 (13), 2285-2302, (2014). https://dx.doi.org/10.1177/0954406213518196

10 Qiu Z. C., Wang B., Zhang X. M., Han J. D. Direct adaptive fuzzy control of a translating piezoelectric flexible manipulator driven by a pneumatic rodless cylinder. Mechanical Systems and Signal Processing 36 (2), 290-316, (2013). https://dx.doi.org/10.1016/j.ymssp.2012.10.008

11 Wang J., Rad A. B. and Chan P. T. Indirect adaptive fuzzy sliding mode control: Part I: fuzzy switching. Fuzzy Sets and Systems 122 (1), 21-30, (2001). https://dx.doi.org/10.1016/S0165-0114(99)00179-7

12 Fei J. T., Xin M. Y., and Juan W. R. Adaptive fuzzy sliding mode control using adaptive sliding gain for MEMS gyroscope. Transactions of the Institute of Measurement and Control 35 (4), 551-558, (2013). https://dx.doi.org/10.1177/0142331212455451

13 Kim B. S., Han S. I., and Lee J. M. Adaptive fuzzy output feedback dynamic surface sliding mode control for a nonlinear dynamic system. Proc IMechE Part I: Journal of Systems and Control Engineering 227 (2), 214-229, (2013). https://dx.doi.org/10.1177/0959651812463507 